\title{
ENSINO A DISTÂNCIA: UM PANORAMA DA EXPANSÃO NA REGIÃO NORTE DO BRASIL
}

DISTANCE LEARNING: A PANORAMA OF EXPANSION IN NORTHERN BRAZIL

\section{ENSINO A DISTANCIA: UN PANORAMA DE LA EXPANSIÓN EN LA REGIÓN NORTE DE BRASIL}

\section{Jonas Fernando Petry}

Universidade Regional de Blumenau-FURB

Doutorando do Programa de Pós-Graduação em Ciências Contábeis e Administração da Universidade Regional de Blumenau (FURB)

Endereço: R. Antônio da Veiga, 140, Victor Konder, Blumenau - SC, Brasil

E-mail: jonaspetry@brturbo.com.br

\section{Gustavo da Rosa Borges}

Universidade Regional de Blumenau-FURB

Doutorando do Programa de Pós-Graduação em Ciências Contábeis e Administração da Universidade Regional de Blumenau (FURB)

Endereço: R. Antônio da Veiga, 140, Victor Konder, Blumenau - SC, Brasil

E-mail: gustavodarosaborges@gmail.com

\section{Maria José Carvalho de Souza Domingues}

Universidade Regional de Blumenau -FURB

Doutora em Eng. de Produção pela Universidade Federal de Santa Catarina- UFSC

Professora do programa de pós-graduação da Universidade Regional de Blumenau- FURB

Endereço: R. Antônio da Veiga, 140, Victor Konder, Blumenau - SC, Brasil

E-mail: mjcsd2008@gmail.com

Artigo recebido em 20/08/2014. Revisado por pares em 25/11/2014. Reformulado em 27/11/2014. Recomendado para publicação em 27/11/2014 por Ademar Dutra (Editor Científico). Publicado em 30/12/2014. Avaliado pelo Sistema double blind review.
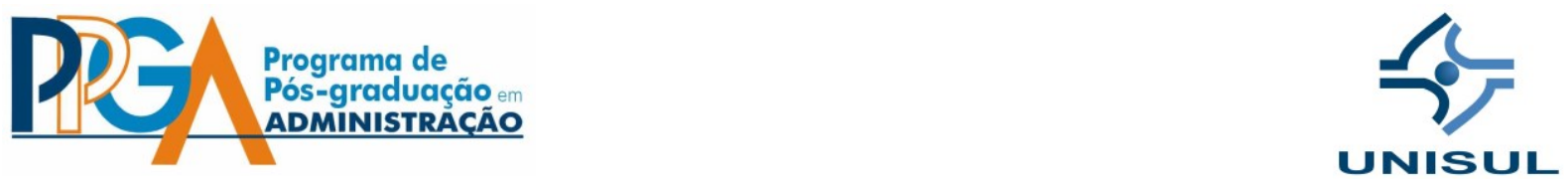

(1) $(9)$

CCopyright 2008 UNISUL-PPGA/Revista Eletrônica de Estratégia \& Negócios. Todos os direitos reservados. Permitida citação parcial, desde que identificada a fonte. Proibida a reprodução total. 
RESUMO

Este estudo tem como objetivo, por meio de um exame transversal descritivo e analítico do conjunto de variáveis qualitativas nominais e ordinais, através da estatística descritiva, expor uma perspectiva sobre a EaD no Norte do Brasil. A análise realizada demonstra uma conquista de espaço desta modalidade de educação em relação à de ensino presencial. Os resultados apontam o reconhecimento da EaD como um método de ensino. No entanto, o discurso da democratização do ensino e da redução das desigualdades está limitado pela privação de tecnologias, principalmente o acesso à internet no Norte do país.

Palavras-chave: Gestão pública; Políticas públicas; Ensino a distância; Expansão da EaD.

\section{ABSTRACT}

This study aims, through a cross-sectional descriptive and analytical examination of the set of nominal and ordinal qualitative variables using descriptive statistics, exposing a perspective on distance education in Northern Brazil. The analysis demonstrates an achievement of the EAD space in relation to the mode of classroom teaching. The results show the recognition of ODL as a teaching method. However, the discourse of democratization of education and the reduction of inequalities is limited by deprivation of technologies, mainly Internet access in the North Country.

Key-words: Public management; Public policy; Distance learning; Expansion of distance education.

\section{RESUMEN}

Este estudio tiene como objetivo, por medio de un examen transversal descriptivo y analítico del conjunto de variables cualitativas nominales y ordinales, a través de estadística descriptiva, exponer una perspectiva sobre la EaD en Norte de Brasil. El análisis realizado demuestra una conquista de espacio de esta modalidad de educación en relación con la enseñanza presencial. Los resultados apuntan lo reconocimiento de EaD como un método de enseñanza. Sin embargo, el discurso de democratización de la enseñanza y de reduccón de las desigualdades está limitado por la privación de tecnologías, principalmente el acceso a internet en Norte del país.

Palabras-clave: Administración pública; Políticas públicas; Enseñanza a distancia; Expansión de la EaD. 


\section{INTRODUÇÃO}

As instituições de ensino, nas últimas décadas, sofreram diversas mudanças: um número significativo de estruturas sociais estabelecidas não suportaram os impactos e fecharam em face de orçamentos mais apertados, o impacto das inovações tecnológicas, as mudanças dos clientes, as demandas estudantis, o isolamento acadêmico, e a menor demanda do mercado. Isto tem sido parte dos debates sobre o futuro da educação em países como Austrália, Estados Unidos e Reino Unido há décadas (WILLARD; WILSON, 2004).

Os impactos da crise no ensino têm levado ao realinhamento organizacional de unidades autônomas independentes e a fusões, tendo em vista a necessidade da redução de custos, da racionalização das estruturas e dos programas. As instituições que expandiram e têm-se saído melhor nos últimos anos foram as que melhor aplicaram seus recursos em áreas de Tecnologia da Informação (TI) (HILDRETH; KOENIG, 2002). O fenômeno do realinhamento e fusão de instituições privadas também se evidenciou no Brasil nos últimos anos. Mais recentemente, o panorama parece refletir a crença de que algumas instituições teriam aproveitado as oportunidades, concentrando-se mais na informação e na aplicação da Tecnologia da Informação.

A quantidade crescente de pesquisas, nos últimos anos, tem chamado a atenção ao número de iniciativas dos incipientes modos de socialização e mediação do ensino (GATTI, 2008; ALMEIDA, 2009). O ensino a distância (EaD) é uma modalidade que usa a tecnologia como principal aliada, implicando transformações na configuração do ensino brasileiro (MENDES, 2011).

Essa modalidade de ensino tem reclamado considerável atenção na literatura em relação às mudanças necessárias ao futuro da ciência da educação. Educadores, de maneira geral, reconheceram a necessidade e a importância de projetar, na educação, elementos sensíveis à rápida e contínua mudança tecnológica e ao desenvolvimento de currículos dinâmicos, que acomodem as exigências do amplo e diversificado mercado de trabalho (PARTRIDGE et al., 2010; PARTRIDGE; YATES, 2012).

O ensino a distância, também chamado de educação a distância (BELLONI, 2009), elearning e ou aprendizagem on-line, está crescendo em popularidade. Na verdade, muitos 
profissionais têm obtido seu bacharelado ou licenciatura dessa forma. Os alunos, muitas vezes, preferem a EaD porque Ihes permite um horário mais flexível do que os programas tradicionais de educação, assim concedendo que gerenciem mais facilmente as exigências de suas carreiras e sua formação (DEGON, 2010). O ensino a distância tradicionalmente tem-se centrado nos estudantes não tradicionais, como trabalhadores, militares e não residentes, ou pessoas em regiões remotas que estão incapazes de participar do ensino tradicional em sala de aula (SCHNITMAN, 2010; CREASE, 2011).

A EaD, no Brasil, vem conquistando seu espaço, ainda que de forma tímida diante dos desafios, e pusilânime diante das incitações de concepções equivocadas. Os programas do governo visam a facilitar o acesso à Educação Superior para as mais variadas classes sociais, por exemplo: através do Sistema de Seleção Unificada (SiSU), Programa Universidade para Todos (ProUni), o Fundo de Financiamento Estudantil (Fies) e a Universidade Aberta do Brasil (UAB) (GATTI, 2008). Estes desígnios têm contribuído para a expansão da EaD, possibilitando o acesso ao conhecimento e à aprendizagem em tempo e espaço adaptáveis à rotina do educando (BELLONI, 2002), oportunizando, aos sujeitos, o acesso ao conhecimento produzido e à produção do conhecimento (MESSIAS, 2010).

Desde a década de noventa, a expansão da EaD na Educação Superior responde por demandas do mundo do trabalho dirigidas à formação de profissionais capazes de garantir a competitividade de organizações no cenário da globalização da economia e, de outro, a políticas educacionais que visam a ampliar a oferta de vagas no ensino de graduação (VILARINHO; PAULINO, 2010).

A EaD tornou-se uma parte estabelecida do mundo educacional com as tendências que apontam para um crescimento contínuo, e as instituições da educação superior procuraram responder aos desafios da Educação a Distância através da adoção de uma série de abordagens que efetivamente praticam essa modalidade de ensino.

Partindo dos debates sobre mudanças na configuração dos setores de ensino e o futuro da educação nos países desenvolvidos, tais debates também atingiram o Brasil. 0 resultado foi um profundo impacto, principalmente nas universidades privadas, reclamando realinhamento e fusões das instituições. O panorama parece refletir a crença de que 
algumas instituições teriam aproveitado a oportunidade, concentrando-se mais na informação e aplicações da Tecnologia da Informação.

O objetivo principal deste constructo é fornecer, através de um estudo transversal descritivo e analítico, uma perspectiva sobre a EaD e sua expansão no Norte do Brasil, analisando o número de cursos na modalidade e instituições presentes que têm contribuído para que o ensino chegue a essa região.

Além da introdução, o presente estudo está apresentado em mais seis seções. A seção 2 foi dedicada à fundamentação teórica, destacando a evolução da EaD e sua definição no Brasil. Na seção 3 são apresentados os procedimentos metodológicos adotados e os dados obtidos através do Ministério de Educação (MEC). A seção 4 investiga a análise dos dados. Na seção 5, discute-se os resultados obtidos e sua análise. As conclusões estão relatadas na seção 6, seguida pelas referências.

\section{FUNDAMENTAÇÃO TEÓRICA}

\subsection{EVOLUÇÃO DO ENSINO A DISTÂNCIA}

O EaD pode parecer um fenômeno relativamente novo, dada sua crescente popularidade no formato on-line. Na realidade, as pessoas foram realizando cursos oferecidos por instrutores a distância por centenas de anos.

Um dos primeiros registros sobre o ensino a distância remonta a 1728, com lições enviadas semanalmente por correspondência aos alunos. Essas lições simples e práticas eram comumente remetidas através do correio, ao longo de 1700 e 1800. Isso tornou possível o ensino profissionalizante a pessoas que viviam em locais distantes dos centros de ensino e do comércio (MATTHEWS, 1999; MONOLESCU et al., 2004; HOLMBERG et al., 2005).

O Ensino a Distância tem suas origens nos meados do século XIX na Europa e nos Estados Unidos. Os pioneiros da Educação a Distância utilizaram a melhor tecnologia do seu dia, o sistema postal, para abrir oportunidades educacionais para as pessoas que queriam aprender, mas não tinham sido capazes de frequentar escolas convencionais. O refinamento e a expansão dos sistemas postais nos EUA e no exterior estão nos fundamentos dos 
ENSINO A DISTÂNCIA: UM PANORAMA DA EXPANSÃO NA REGIÃO NORTE DO BRASIL

Jonas Fernando Petry - Gustavo da Rosa Borges - Maria José Carvalho de Souza Domingues

verdadeiros princípios da aprendizagem a distância. O reconhecimento acadêmico da EaD foi alcançado em 1892, quando a Universidade de Chicago criou o primeiro programa de Educação a Distância de nível universitário (HOLMBERG et al., 2005; CASEY, 2008).

\section{O tratado das datas históricas do Ensino a Distância é ilustrado no Quadro 1.}

\section{Quadro 1 - Educação a distância ao longo da história}

\begin{tabular}{|c|c|}
\hline 1728 & $\begin{array}{l}\text { O relato do primeiro curso de ensino a distância do mundo é estabelecido em Boston, com lições } \\
\text { enviadas por correspondência. }\end{array}$ \\
\hline 1829 & $\begin{array}{l}\text { Na Suécia, é inaugurado o Instituto Líber Hermondes, que possibilitou a mais de } 150.000 \text { pessoas } \\
\text { realizarem cursos através da Educação a Distância. }\end{array}$ \\
\hline 1840 & $\begin{array}{l}\text { Na Grã-Bretanha, o inventor Saac Pitman foi um educador e inventor inglês que criou um método } \\
\text { de taquigrafia (ou estenografia) à base de fichas instrutivas, que eram trocadas por } \\
\text { correspondência com seus alunos. O conceito de Pitman, em poucos anos, alcançou um número } \\
\text { expressivo de alunos distantes e, em algumas décadas, os programas estavam disponíveis no } \\
\text { Reino Unido, Alemanha, Estados Unidos e Japão. }\end{array}$ \\
\hline 1850 & $\begin{array}{l}\text { Agricultores e pecuaristas europeus aprendiam, por correspondência, como plantar ou qual a } \\
\text { melhor forma de cuidar do rebanho. }\end{array}$ \\
\hline 1856 & $\begin{array}{l}\text { Em Berlim, a Sociedade de Línguas Modernas patrocina os professores Charles Toussaine e Gustav } \\
\text { Laugenschied para ensinarem Francês por correspondência. }\end{array}$ \\
\hline 1892 & Universidade de Chicago cria o primeiro programa de EaD de nível universitário. \\
\hline 1900 & $\begin{array}{l}\text { Foi criado o primeiro departamento de ensino por correspondência estabelecido na Universidade } \\
\text { de Chicago. }\end{array}$ \\
\hline $1904^{*}$ & $\begin{array}{l}\text { O Jornal do Brasil registra, na primeira edição da seção de classificados, anúncio que oferece } \\
\text { profissionalização por correspondência para datilógrafo. }\end{array}$ \\
\hline 1911 & Na Austrália, a universidade de Queensland estabeleceu um departamento de estudos externos. \\
\hline 1922 & Penn State começa a oferecer cursos através do rádio. \\
\hline 1922 & Iniciam-se cursos por correspondência na União Soviética. \\
\hline 1923* & $\begin{array}{l}\text { Um grupo liderado por Henrique Morize e Edgard Roquette-Pinto criou a Rádio Sociedade do Rio } \\
\text { de Janeiro, que oferecia cursos de Português, Francês, Silvicultura, Literatura Francesa, Esperanto, } \\
\text { Radiotelegrafia e Telefonia. Tinha, assim, o início da EaD pelo rádio brasileiro. }\end{array}$ \\
\hline 1925 & Mais de 2000 licenças de radiodifusão foram concedidas para faculdades e universidades. \\
\hline 1934* & $\begin{array}{l}\text { Edgard Roquette-Pinto instalou a Rádio-Escola Municipal no Rio, projeto para a então Secretaria } \\
\text { Municipal de Educação do Distrito Federal. }\end{array}$ \\
\hline 1935 & $\begin{array}{l}\text { O Japanese National Public Broadcasting Service inicia seus programas escolares pelo rádio, como } \\
\text { complemento e enriquecimento da escola oficial. }\end{array}$ \\
\hline 1939* & $\begin{array}{l}\text { É criado, em São Paulo, o Instituto Monitor, primeiro instituto brasileiro a oferecer cursos } \\
\text { profissionalizantes a distância por correspondência, na época ainda com o nome Instituto Rádio } \\
\text { Técnico Monitor. }\end{array}$ \\
\hline 1941* & Surge o Instituto Universal Brasileiro. \\
\hline $1941^{*}$ & Surge a primeira Universidade do Ar, que durou até 1944. \\
\hline $1947^{*}$ & $\begin{array}{l}\text { Reabertura da nova Universidade do Ar, patrocinada pelo Serviço Nacional de Aprendizagem } \\
\text { Comercial (SENAC), Serviço Social do Comércio (SESC) e emissoras associadas. O objetivo era } \\
\text { oferecer cursos comerciais radiofônicos. Os alunos estudavam nas apostilas e corrigiam exercícios } \\
\text { com o auxílio dos monitores. A experiência durou até 1961; entretanto, a experiência do SENAC } \\
\text { com a Educação a Distância continua até hoje. }\end{array}$ \\
\hline 1947 & $\begin{array}{l}\text { Inicia-se a transmissão das aulas de quase todas as matérias literárias da Faculdade de Letras e } \\
\text { Ciências Humanas de Paris, França, por meio da Rádio Sorbonne. }\end{array}$ \\
\hline 1948 & É criada a primeira legislação para escolas por correspondência na Noruega. \\
\hline 1951 & $\begin{array}{l}\text { Criada a Universidade de Sudáfrica, atualmente a única universidade a distância da África, que se } \\
\text { dedica exclusivamente a desenvolver cursos nesta modalidade. }\end{array}$ \\
\hline
\end{tabular}


ENSINO A DISTÂNCIA: UM PANORAMA DA EXPANSÃO NA REGIÃO NORTE DO BRASIL

Jonas Fernando Petry - Gustavo da Rosa Borges - Maria José Carvalho de Souza Domingues

120

\begin{tabular}{|c|c|}
\hline 1956 & $\begin{array}{l}\text { A Chicago TV College, nos Estados Unidos, inicia a transmissão de programas educativos pela } \\
\text { televisão, cuja influência pode-se notar rapidamente em outras universidades do País. }\end{array}$ \\
\hline 1959* & $\begin{array}{l}\text { A Diocese de Natal, Rio Grande do Norte, cria algumas escolas radiofônicas, dando origem ao } \\
\text { Movimento de Educação de Base (MEB). }\end{array}$ \\
\hline 1960 & $\begin{array}{l}\text { Nasce na Argentina a Tele Escola Primária do Ministério da Cultura e Educação, que integrava os } \\
\text { materiais impressos à televisão e à tutoria. }\end{array}$ \\
\hline $1962^{*}$ & $\begin{array}{l}\text { É fundada, em São Paulo, a Ocidental School, de origem americana, focada no campo da } \\
\text { eletrônica. }\end{array}$ \\
\hline 1965 & $\begin{array}{l}\text { É criado o primeiro programa de educação de abrangência nacional nos Estados Unidos, oferecido } \\
\text { através do telefone pela Universidade de Wisconsin. }\end{array}$ \\
\hline $1967^{*}$ & $\begin{array}{l}\text { O Instituto Brasileiro de Administração Municipal inicia suas atividades na área de educação } \\
\text { pública, utilizando-se da metodologia de ensino por correspondência. }\end{array}$ \\
\hline $1967^{*}$ & $\begin{array}{l}\text { A Fundação Padre Landell de Moura criou seu núcleo de Educação a Distância com metodologia } \\
\text { de ensino por correspondência e via rádio. }\end{array}$ \\
\hline 1968 & $\begin{array}{l}\text { A Universidade de Stanford funda a rede de televisão instrucional Stanford, oferecendo instrução } \\
\text { para estudantes de engenharia em tempo parcial. }\end{array}$ \\
\hline 1968 & $\begin{array}{l}\text { Criada a Universidade do Pacífico Sul, uma universidade regional que pertence a } 12 \text { países-ilhas da } \\
\text { Oceania. }\end{array}$ \\
\hline 1969 & O Departamento de Defesa dos EUA cria a internet (ARPANET). \\
\hline 1969 & É criada a Fundação da Universidade Aberta no Reino Unido. \\
\hline $1970^{*}$ & $\begin{array}{l}\text { Surge o Projeto Minerva, um convênio entre o MEC, Fundação Padre Landell de Moura e a } \\
\text { Fundação Padre Anchieta, cuja meta era a utilização do rádio para a educação e a inclusão social } \\
\text { de adultos. O projeto foi mantido até o início da década de } 1980 \text {. }\end{array}$ \\
\hline 1971 & $\begin{array}{l}\text { O crítico e sociólogo Ivan Illich escreve Sociedade sem Escolas, que descreve a educação baseada } \\
\text { em computador. }\end{array}$ \\
\hline 1971 & a Universidade Aberta Britânica. \\
\hline 1972 & Educação a Distância na Espanha. \\
\hline $1974^{*}$ & Surge o Ir \\
\hline 1974* & $\begin{array}{l}\text { Com material televisivo, impresso e monitores, a TV Ceará inicia os cursos das antigas } 5^{\text {a }} \text { à } 8^{\mathrm{a}} \\
\text { séries (hoje Ensino Fundamental). }\end{array}$ \\
\hline $1976^{*}$ & É criado o Sistema Nacional de Teleducação, com cursos através de material instrucional. \\
\hline 1977 & $\mathrm{Na}$ Venezuela é cr \\
\hline 1976 & $\begin{array}{l}\text { Universidade de Phoenix é fundada para oferecer, aos adultos que trabalham, opções flexíveis de } \\
\text { Educação Superior. Hoje, os alunos aprendem em mais de } 200 \text { locais - e por meio de programas } \\
\text { on-line que abrangem todo o globo. }\end{array}$ \\
\hline 1978 & Na Costa Rica é fundada a Universidade Estadual a Distância. \\
\hline $1978^{*}$ & $\begin{array}{l}\text { Estreia do Telecurso } 2 \text { o grau, uma id } \\
\text { instrumento para levar educação ao } n\end{array}$ \\
\hline 1979* & $\begin{array}{l}\text { A Universidade de Brasília cria cursos veiculados por jornais e revistas que, em 1989, é } \\
\text { transformado no Centro de Educação Aberta, Continuada, a Distância (CEAD), lançando no Brasil } \\
\text { no formato EAD. }\end{array}$ \\
\hline 1981 & $\begin{array}{l}\text { É fundado o Centro Internacional de Estudos Regulares (CIER) do Colégio Anglo-Americano, que } \\
\text { oferecia Ensino Fundamental e Médio a distância. }\end{array}$ \\
\hline 1981* & $\begin{array}{l}\text { Criado o Telecurso } 1 \text { o grau. Assistindo aos programas e comprando os fascículos que eram } \\
\text { vendidos nas bancas, as pessoas podiam concluir os ensinos Fundamental e Médio (na época } \\
\text { chamados de } 1 \text { e e } 20 \text { graus). O diploma era conseguido por meio das provas aplicadas pelo próprio } \\
\text { governo. } \\
\text { Em 1995, os dois programas foram substituídos pelo Telecurso } 2000 \text {. } \\
\text { Em 2008, uma última mudança: o tradicional programa passou a ser chamado de Novo Telecurso. }\end{array}$ \\
\hline 1982 & $\begin{array}{l}\text { É instituído a CALC (Computer Assisted Learning Center), um centro de aprendizagem para os } \\
\text { adultos baseada em computador. }\end{array}$ \\
\hline 1983 & $\begin{array}{l}\text { O SENAC desenvolveu uma série de programas radiofônicos sobre orientação profissional na área } \\
\text { de comércio e serviços, denominada Abrindo Caminhos. }\end{array}$ \\
\hline 1984 & É implantada a Universidade Aberta da Holanda. \\
\hline 1985 & \\
\hline 1985 & tação da Universidade Nacional Aberta Indira Gandhi. \\
\hline
\end{tabular}

Revista Eletrônica de Estratégia \& Negócios, Florianópolis, v.7, n.3, set./dez. 2014. 


\begin{tabular}{|c|c|}
\hline 1987 & $\begin{array}{l}\text { É divulgada a resolução do Parlamento Europeu sobre Universidades Abertas na então } \\
\text { Comunidade Europeia. }\end{array}$ \\
\hline 1987 & Criada a Fundação da Associação Europeia de Universidades de Ensino a Distância. \\
\hline 1988 & É criada a Fundação da Universidade Aberta em Portugal. \\
\hline 1990 & $\begin{array}{l}\text { Implantada a rede Europeia de Educação a Distância, baseada na declaração de Budapeste e no } \\
\text { relatório da Comissão sobre educação aberta e a distância na Comunidade Europeia. }\end{array}$ \\
\hline 1991* & $\begin{array}{l}\text { O programa Jornal da Educação - Edição do Professor, concebido e produzido pela Fundação } \\
\text { Roquete-Pinto tem início e, em 1995, com o nome Um Salto para o Futuro, foi incorporado à TV } \\
\text { Escola (canal educativo da Secretaria de Educação a Distância do Ministério da Educação), } \\
\text { tornando-se um marco na Educação a Distância nacional. }\end{array}$ \\
\hline 1992* & É criada a Universidade Aberta de Brasília. \\
\hline 1992 & $\begin{array}{l}\text { A rede da universidade eletrônica oferece um programa de Ph.D. via America Online. Os } \\
\text { programas incluem um Ph.D. em estudos integrais. }\end{array}$ \\
\hline 1994 & Os primeiros currículos completamente on-line são introduzidos por CALCampus. \\
\hline 1995* & $\begin{array}{l}\text { É criado o Centro Nacional de Educação a Distância e, neste mesmo ano, também a Secretaria } \\
\text { Municipal de Educação cria a MultiRio (RJ), que ministra cursos do } 60 \text { ao } 90 \text { ano através de } \\
\text { programas televisivos e material impresso. }\end{array}$ \\
\hline 1995* & Criado o Programa TV Escola da Secretaria de Educação a Distância do MEC. \\
\hline 1995 & $\begin{array}{l}\text { Representantes de universidades americanas encontram-se nos EUA com } 19 \text { governadores para } \\
\text { ajudar os estados ocidentais a maximizar recursos educacionais através de ensino a distância para } \\
\text { a população em rápido crescimento. }\end{array}$ \\
\hline 1996* & $\begin{array}{l}\text { É criada a Secretaria de Educação a Distância (SEED), pelo MEC, dentro de uma política que } \\
\text { privilegia a democratização e a qualidade da educação brasileira. } \\
\text { É neste ano também que a Educação a Distância surge oficialmente no Brasil. }\end{array}$ \\
\hline 1996* & $\begin{array}{l}\text { Marco oficial do surgimento da EaD no Brasil com bases legais para essa modalidade de educação, } \\
\text { estabelecidas pela Lei de Diretrizes e Bases da Educação Nacional n } 9.394 \text {, de } 20 \text { de dezembro de } \\
\text { 1996, embora somente regulamentada em } 20 \text { de dezembro de } 2005 \text { pelo Decreto } n^{\circ} 5.622 \\
\text { (BRASIL, 2005), que revogou os Decretos } n^{\circ} 2.494 \text { de } 10 / 02 / 98 \text {, e } n^{\circ} 2.561 \text { de } 27 / 04 / 98 \text {, com } \\
\text { normatização definida na Portaria Ministerial n } 4.361 \text { de } 2004 \text {. }\end{array}$ \\
\hline 1997 & $\begin{array}{l}\text { Um consórcio de universidades da Califórnia CVU (California Virtual University), que oferecem } \\
\text { mais de } 1.000 \text { cursos on-line, é lançado. }\end{array}$ \\
\hline 1999 & $\begin{array}{l}\text { O mundo é apresentado a uma série de novas ferramentas de ensino, incluindo a lousa digital e o } \\
\text { eCollege. }\end{array}$ \\
\hline 1999 & $\begin{array}{l}\text { Tutoria on-line (smartthinking) também chega em 1999, com a missão de ser uma "empresa } \\
\text { inovadora em conectar os alunos com professores altamente qualificados" através da internet. }\end{array}$ \\
\hline $2000^{*}$ & $\begin{array}{l}\text { É formada a UniRede, Rede de Educação Superior a Distância, consórcio que reúne atualmente } 70 \\
\text { instituições públicas do Brasil . }\end{array}$ \\
\hline $2000^{*}$ & É criado o Centro de Educação a Distância do Estado do Rio de Janeiro (CEDERJ). \\
\hline $2002 *$ & $\begin{array}{l}\text { O CEDERJ é incorporado à Fundação Centro de Ciências de Educação Superior a Distância do Rio } \\
\text { de Janeiro (Fundação CECIERJ). }\end{array}$ \\
\hline 2002 & O curso do projeto lousa aberta, um recurso de materiais online do MIT se torna disponível. \\
\hline 2003 & $81 \%$ das faculdades têm, pelo menos, uma aula on-line. \\
\hline $2004 *$ & $\begin{array}{l}\text { Vários programas para a formação inicial e continuada de professores da rede pública, por meio } \\
\text { da EaD, foram implantados pelo MEC. Entre eles o Proletramento e as Mídias na Educação. }\end{array}$ \\
\hline $2005 *$ & $\begin{array}{l}\text { É criada a Universidade Aberta do Brasil, uma parceria entre o MEC, estados e municípios, } \\
\text { integrando cursos, pesquisas e programas de Educação Superior a distância. }\end{array}$ \\
\hline $2006^{*}$ & $\begin{array}{l}\text { Entra em vigor o Decreto } n^{\circ} 5.773 \text {, de } 09 \text { de maio de } 2006 \text {, que dispõe sobre o exercício das } \\
\text { funções de regulação, supervisão e avaliação de instituições de educação superior e cursos } \\
\text { superiores de graduação e sequenciais no sistema federal de ensino. }\end{array}$ \\
\hline $2007^{*}$ & $\begin{array}{l}\text { Entra em vigor o Decreto no 6.303, de } 12 \text { de dezembro de 2007, que altera dispositivos do Decreto } \\
n^{\circ} 5.622 \text {, que estabelece as Diretrizes e Bases da Educação Nacional (BRASIL, 2007). }\end{array}$ \\
\hline $\begin{array}{l}2002- \\
2008\end{array}$ & $\begin{array}{l}\text { Khan Academy é fundada com a missão de oferecer uma educação de classe mundial, livre para os } \\
\text { alunos através de materiais on-line, que incluem milhares de vídeos, resolução de problemas } \\
\text { passo a passo e dados imediatos. } \\
\text { O primeiro programa de ambiente virtual é usado para treinar os paramédicos em Londres. } \\
\text { StraighterLine é fundada e começa a ligar os alunos on-line com as ferramentas nesta modalidade. }\end{array}$ \\
\hline
\end{tabular}




\begin{tabular}{|c|c|}
\hline & Centenas de faculdades e universidades são credenciadas em todo o país. \\
\hline $2008^{*}$ & $\begin{array}{l}\text { Em São Paulo, uma lei permite o Ensino Médio a distância, onde até } 20 \% \text { da carga horária poderá } \\
\text { ser não presencial. }\end{array}$ \\
\hline 2009* & $\begin{array}{l}\text { Entra em vigor a Portaria no 10, de } 02 \text { de julho de 2009, que fixa critérios para a dispensa de } \\
\text { avaliação in loco, e deu outras providências para a Educação a Distância na educação superior no } \\
\text { Brasil. }\end{array}$ \\
\hline 2009 & O número de alunos matriculados em pelo menos um curso on-line chega a 5,5 milhões. \\
\hline 2010 & $\begin{array}{l}83 \% \text { dos CEO e donos de pequenos negócios, nos Estados Unidos, consideram os cursos on-line } \\
\text { tão credíveis como cursos tradicionais. }\end{array}$ \\
\hline $2011^{*}$ & A Secretaria de Educação a Distância é extinta no Brasil. \\
\hline 2012 & $\begin{array}{l}96 \% \text { das universidades tradicionais oferecem cursos on-line. } \\
\text { Dois milhões de estudantes fazem, todos os seus, cursos nesta modalidade. } \\
\text { Mais de } 50 \text { mil pesquisas são feitas a cada mês para palavras-chave relacionadas com } \\
\text { universidades on-line; } 70 \% \text { dos educadores concordam que a mídia social é uma valiosa } \\
\text { ferramenta de ensino. }\end{array}$ \\
\hline $\begin{array}{l}\text { Projeções } \\
\text { futuras... }\end{array}$ & $\begin{array}{l}\text { Em um futuro próximo, Harvard e MIT lançarão EDX, um recurso on-line disponível gratuitamente } \\
\text { para qualquer pessoa com uma conexão à Internet. } \\
\text { Na próxima década, estima-se que a percentagem de empregos que exigem algumas habilidades } \\
\text { tecnológicas passará de } 50 \% \text { para } 77 \% \text {, de onde decorre a necessidade urgente de ampliar a } \\
\text { capacidade da EaD. } \\
\text { Em } 2014 \text {, o número de estudantes universitários que tomam pelo menos uma aula on-line deverá } \\
\text { quadruplicar de } 4,6 \text { milhões para } 18,65 \text { milhões. } \\
\text { Em } 2015 \text {, os cursos de nível superior on-line estão esperando um aumento de } 37 \% \text { de inscritos. }\end{array}$ \\
\hline
\end{tabular}

* datas históricas da EaD no Brasil

Fonte: Adaptado de Alves (2011, p. 4-8).

A modalidade de ensino remonta a uma longa história, sendo difícil definir o marco ou o momento de sua fundação (VILAÇA, 2010). A história da Educação a Distância revela uma jornada de formação profissional que contrasta com o tutorial antigo, em que um professor e um aluno individual reuniam-se ao mesmo tempo e lugar, e o modelo contemporâneo mais familiar de instrução em sala de aula, onde um professor fala para um grupo de alunos, todos juntos, ao mesmo tempo, no mesmo lugar. Contudo, se o professor e os estudantes não estão juntos no mesmo local ou em conjunto ao mesmo tempo, então estão separados por uma distância e, como resultado, torna-se necessário introduzir um meio de comunicação artificial que fornecerá informação, bem como proporcionar um canal para a sua interação (MOORE; KEARSLEY, 2011).

A EaD é menos uma filosofia e mais um método de educação. Os alunos podem estudar em seu próprio tempo, no lugar de sua escolha (casa, trabalho ou centro de aprendizagem), e sem contato face to face com um professor. A tecnologia é um elemento fundamental da Educação a Distância (BATES, 2005).

\subsection{DEFINIÇÃO DO ENSINO A DISTÂNCIA}


Para a definição do Ensino a Distância ou Educação a Distância, existem várias conceituações de educação de primeira e segunda geração. Referem-se a: (i) cursos por correspondência, cursos de extensão, estudos estendidos; (ii) estudo de casa, educação continuada, estudos externos; (iii) estudos self-paced, estudos independentes, ensino a distância. A terceira e quarta gerações descrevem o Ensino a Distância incluindo os seguintes termos: (i) cyber-educação, educação on-line, educação virtual; (ii) educação apoiada em tecnologia, educação híbrida, aprendizagem distribuída; (iii) e-learning, educação baseada na Web. Proporcionar Educação a Distância é a definição mais simples desta modalidade de educação. Hoje em dia, a Educação a Distância, e-learning, educação virtual, ou qualquer outro nome que se queira definir é, basicamente, um método de ensino onde o aluno e o instrutor são separados pelo tempo ou no espaço, ou ambos (NASSEH, 1997).

Teóricos da Educação a Distância têm abordado as principais questões no campo da EaD a partir de uma perspectiva holística. As teorias da Educação a Distância têm sido conceituadas e desenvolvidas por europeus, australianos e canadenses, abordando questões fundamentais, tais como a forma de definir suas características e como distinguir a Educação a Distância a partir de outras formas de educação. Ao olhar para a Educação a Distância a partir de uma perspectiva mais ampla, os principais teóricos do campo convergem na ideia da centralidade do aluno, que é uma das características distintivas da EaD, e na forma como o campo está organizado e como funciona, fatos que fazem com que esta modalidade seja diferente de outras formas de educação (SABA, 2003).

O conceito fundamental de Educação a Distância é bastante simples: os alunos e professores estão separados pela distância e, algumas vezes, pelo tempo (MOORE; KEARSLEY, 2011). A EaD é um conceito que abrange as atividades de ensino-aprendizagem nos aspectos cognitivos e/ou no domínio psicomotor e afetivo de um aluno individual e uma organização de apoio. É caracterizado por uma comunicação não contígua, e as referidas atividades podem ser realizadas em qualquer local e em qualquer momento, o que faz com que sejam atraentes para os adultos com compromissos profissionais e sociais. A EaD caracteriza-se por ensinar e aprender através da mídia; em princípio, os alunos e seus professores não se encontram face a face. Um ou mais meios de comunicação podem ser utilizados para a interação e a comunicação sobre o assunto, por exemplo, apostilas, 
material impresso, áudio e vídeo, conversas telefônicas, comunicação através da rede de computadores (HOLMBERG et al., 2005).

A definição tradicional de Educação a Distância está lentamente sendo alterada à medida que surgem novas tecnologias educacionais. A EaD inclui as várias formas de estudo em todos os níveis que não estão sob a supervisão imediata e contínua de tutores presentes com seus alunos em salas de aula no mesmo local, e que, no entanto, se beneficiam do planejamento, orientação e instrução de uma organização tutorial (HOLMBERG, 1986). Assim, a instrução pode ser síncrona ou assíncrona, e envolver a comunicação através do uso de tecnologias de vídeo, de áudio ou computador, ou por correspondência (que pode incluir tanto a escrita como a utilização de tecnologias, tais como CD-ROM) (PARSAD et al., 2008).

Nos últimos anos, o campo da EAD tem sofrido alterações drásticas. O que antes era considerado uma forma especial de educação usando sistemas de distribuição não tradicionais, agora está se tornando um importante conceito no Ensino Regular. Conceitos como a aprendizagem em rede, espaços de aprendizagem conectados, aprendizagem flexível e sistemas de aprendizagem híbridos têm ampliado o alcance e mudado a natureza dos modelos de Educação a Distância anteriores. Cursos baseados na web fazem parte de programas tradicionais, acessíveis a qualquer hora, em qualquer lugar (GUNAWARDENA; MCISAAC, 2004).

A Educação a Distância é usada em uma variedade de configurações e para uma ampla gama de propósitos. Universidades a usam para aumentar o número de estudantes que têm acesso à educação superior; empresas a usam para melhorar as competências dos seus trabalhadores e mantê-los a par do rápido avanço tecnológico; indivíduos a usam para seu próprio desenvolvimento profissional e para aumentar suas oportunidades de carreira; governos a usam para fornecer treinamento no local de trabalho; professores e outros profissionais, para melhorar a qualidade do ensino primário e secundário e para publicar instruções para áreas rurais remotas (POTASHNIK; CAPPER, 1998).

A modalidade da EaD oferece, a qualquer pessoa, a oportunidade e o acesso à educação. $\mathrm{O}$ aluno pode aprender sem deixar de lado seu trabalho diário, fazer uso de seu tempo de lazer e, desta forma, adquirir conhecimento e prática. Cada aluno constitui a sua própria classe de escola, ele pode escolher o tempo que lhe convém para o seu estudo e 
pode usar, à vontade, qualquer hora disponível para aprender (HOLMBERG et al., 2005). A EaD já é reconhecida como um método de ensino eficaz e como ferramenta de aprendizagem (SIMONSON et al., 2000). Assim, através da adoção de tecnologias, a internet, principalmente, tem continuado a promover a democratização do ensino, ensinando alguém em qualquer lugar.

\subsection{ENSINO A DISTÂNCIA NO BRASIL}

Conjetura-se que, no Brasil, as primeiras experiências em EaD tenham ficado sem registro, considerando-se que os primeiros assentamentos são do século XX (ALVES, 2011). O marco cronológico da EaD no Brasil é de 1996, com a oficialização da Lei no 9.394/96, que normalizou a Educação a Distância, no país, como modalidade válida e equivalente ao ensino in loco para todos os níveis (COSTA; FARIA, 2008).

O crescimento do emprego de tecnologia na composição de ensino-aprendizagem em diferentes contextos, nos últimos anos, tem feito com que, algumas vezes, os conceitos pareçam ambíguos. Isso é perceptível com o advento e a introdução da educação tecnológica $\mathrm{EaD}$ na modalidade on-line e semipresencial, em que as configurações entre as relações educandos e educadores têm revolucionado o modo peculiar de ensino (VILAÇA, 2010).

As bases legais para a modalidade da EaD, no Brasil, foram estabelecidas pela Lei de Diretrizes e Bases da Educação Nacional (Lei n.o 9.394, de 20 de dezembro de 1996), a qual foi regulamentada pelo Decreto $\mathrm{n}$ - 5.622 de 19 de dezembro de 2005:

Art. 1ㅇ - Para os fins deste Decreto, caracteriza-se a Educação à Distância (sic) como modalidade educacional na qual a mediação didático-pedagógica nos processos de ensino e aprendizagem ocorre com a utilização de meios e tecnologias de informação e comunicação, com estudantes e professores desenvolvendo atividades educativas em lugares ou tempos diversos (BRASIL, 2005).

Observando a evolução dos acontecimentos de nível mundial a respeito da EaD, no Brasil, sua evolução histórica, como pode ser examinado no Quadro 1, é marcada pelo aparecimento e a disseminação dos meios de comunicação. Essa modalidade de educação também passou pela fase da correspondência, do rádio, da televisão, até chegar à atuação conjugada de vários meios de comunicação, o que pode ser evidenciado no Quadro 2, entre eles os favorecidos pelo uso da internet (FARIA; SALVADORI, 2010). O processo de ensino- 
aprendizagem ocorre com a intervenção das tecnologias de informação e comunicação, de forma planejada conforme o enunciado por (MOORE; KEARSLEY, 2007) que the dão suporte.

Quadro 2 - Gerações da Educação a Distância

\begin{tabular}{|l|l|l|}
\hline Geração & \multicolumn{1}{|c|}{ Forma } & \multicolumn{1}{c|}{ Recursos } \\
\hline Primeira & Ensino por Correspondência & Materiais impressos, livros, apostilas. \\
\hline Segunda & Transmissão por rádio e televisão & Rádio, vídeo, TV, fitas cassetes. \\
\hline Terceira & Universidades abertas & Materiais impressos, TV, rádio, telefone, fitas cassete. \\
\hline Quarta & Teleconferência & Teleconferência interativa com áudio. \\
\hline Quinta & Internet/web & $\begin{array}{l}\text { Internet, MP3, ambientes virtuais de aprendizagem } \\
\text { (AVA), vídeos, animações, ambientes 3D, redes sociais, } \\
\text { fóruns. }\end{array}$ \\
\hline
\end{tabular}

Fonte: Vilaça (2010, p. 95).

As mudanças nas configurações das instituições de ensino presencial, no Brasil, têm reunido um número significativo de ofertas de cursos na modalidade EaD, sendo o grande impulsionador da expansão desta modalidade de ensino no país (VILARINHO; PAULINO, 2010).

Aprendizagem on-line é facilitada pela comunicação mediada por computador, que está mudando radicalmente a educação. As discussões sobre os efeitos da tecnologia na EaD não são meras especulações sobre o que o futuro pode trazer. As mudanças estão rapidamente tornando-se parte da prática educacional moderna em todos os níveis. Alguns comentadores têm sugerido, na visão mais crítica, que o impacto dessas mudanças pode ser tão grande que nossas instituições educacionais atuais podem não sobreviver (GARRISON et al., 2003).

\subsubsection{Sistematização da EaD no Brasil}

O debate do conceito e da operação da EaD no Brasil intensificou-se a partir de 2007, com o manifesto da Secretaria de Educação a Distância (SEED) do MEC, segundo o qual a EaD seria uma modalidade semipresencial com políticas públicas, com pautas de apoio a pesquisas e ao desenvolvimento tecnológico e científico de metodologias e de tecnologias que pudessem ser utilizadas no país para promover a qualidade e a ampla difusão da Educação a Distância. A discussão ascende com a publicação do MEC, em setembro de 2007, com a notória avaliação do grau de qualidade alcançada pela EaD no país, de estudo 
comparativo entre o desempenho de alunos de cursos de graduação presenciais, publicado pelo Instituto Nacional de Pesquisas Educacionais Anísio Teixeira (INEP) (VIANNEY, 2008).

A EaD é um processo de ensino-aprendizagem, mediado por tecnologias, onde professores e alunos estão separados espacial e/ou temporalmente. Está representado na Figura 01 pelo conjunto de relações que atuam, em geral, de maneira coordenada.

Antes de escolher um curso, é importante saber o que ele oferece e quais recursos são necessários para ter acesso ao material. Cada instituição apresenta seu próprio formato. Normalmente, as aulas são transmitidas ao vivo, via internet, para os polos de apoio presencial, de acordo com o dia de aula do curso, com ou sem horário determinado. Nos demais dias, o aluno tem à sua disposição, por meio do Ambiente Virtual de Aprendizagem (AVA), o apoio de professores auxiliares para tirar dúvidas e orientar na realização de atividades extraclasse. Periodicamente, são realizadas provas presenciais para atestar a aprendizagem alcançada.

Os Polos de Apoio Presencial oferecem a estrutura tecnológica para a transmissão das aulas e são os espaços onde ocorrem o acompanhamento e a orientação dos estudos e atividades, bem como as avaliações presenciais e a interação entre os estudantes. Os polos são distribuídos por estados e regiões para atender os alunos. Dependendo da modalidade, os polos servem somente como locais para a realização das avaliações presenciais com datas determinadas.

Normalmente, em alguns formatos, o aluno tem acesso ao AVA para materiais de estudo, textos de apoio, vídeos, registros das aulas, trocas de mensagens com os professores e outros estudantes. $\mathrm{O}$ acesso pode ser feito de qualquer computador conectado à internet.

Sem custos adicionais, habitualmente o aluno recebe o material didático que servirá de apoio ao aprendizado das disciplinas. Cada instituição tem suas próprias políticas para a complementação da formação, acesso à biblioteca virtual, livros em formato PDF, portal virtual com disponibilização de venda e locação de livros digitais, filmes e espaço virtual disposto pelo meio de tecnologia. 
A notoriedade do EaD tem sido detalhada nos resultados do ENADE nos últimos anos, comparando o desempenho de alunos a distância e alunos do ensino presencial. Os resultados têm apontado melhor desempenho nas notas dos alunos de curso de graduação a distância (VIANNEY, 2008). A EaD, no país, encontra-se em fase de crescimento, consolidação pedagógica e regulação governamental. O Ensino a Distância é reflexo da evolução tecnológica do mundo virtual, requerendo diretrizes específicas na nova concepção pedagógica e organizações distintas (MORAN, 2009).

O senso realizado pela Associação Brasileira de Ensino a Distância (ABED), em 2012, demonstra que a EaD continua crescendo no Brasil, e confirma a adoção plena dessa modalidade de aprendizagem (ASSOCIAÇÃO BRASILEIRA DE ENSINO A DISTÂNCIA, 2013). Diante da expansão da EaD no país busca-se, através de um estudo transversal e analítico, uma perspectiva sobre esta modalidade de educação e sua difusão espontânea no Norte do Brasil, analisando o número de cursos e instituições presentes que têm contribuído para que o ensino chegue àquela região.

\section{PROCEDIMENTOS METODOLÓGICOS}

Este estudo busca, através de um delineamento transversal descritivo e analítico, traçar uma perspectiva da EaD no contexto da Região Norte do Brasil, analisando o número de cursos na modalidade e instituições presentes que têm contribuído para que o ensino chegue a essa região, conforme mencionado anteriormente. A coleta das informações foi realizada no mês de outubro de 2013 a partir do portal emec.mec.gov.br. O conjunto de variáveis quantitativas da EaD, no contexto da Região Norte do Brasil, através da estatística descritiva de frequência com a utilização do software IBM ${ }^{\circledR}$ SPSS ${ }^{\circledR}$ Statistics, foi representado e sintetizado em tabelas e gráficos para a avaliação. A escolha da amostra compreende todos os cursos da modalidade EaD em atividade listados no site do MEC em 29 outubro de 2013, contemplados na Região Norte do país.

A Região Norte do Brasil é a maior em extensão que corresponde a $42,27 \%$ do território nacional. Compreende sete Estados: Acre, Amapá, Amazonas, Pará, Rondônia, Roraima e Tocantins (INSTITUTO BRASILEIRO DE GEOGRAFIA E ESTATÍSTICA, 2008). A região engloba 449 municípios e 8,31\% da população brasileira (INSTITUTO BRASILEIRO DE GEOGRAFIA E ESTATÍSTICA, 2010). A escolha da Região Norte ocorreu por estar em situação 
ENSINO A DISTÂNCIA: UM PANORAMA DA EXPANSÃO NA REGIÃO NORTE DO BRASIL

Jonas Fernando Petry - Gustavo da Rosa Borges - Maria José Carvalho de Souza Domingues

menos privilegiada em relação às demais unidades federativas, no que diz respeito a distância e ao emprego de tecnologias disponíveis, como a internet. Apesar destas peculiaridades, a região tem aumentado sua participação nos últimos três anos, tendo apresentado, em 2012, um crescimento de 7\% (ASSOCIAÇÃO BRASILEIRA DE EDUCAÇÃO A DISTÂNCIA, 2013).

A representação dos fenômenos e medição das variáveis pela estatística descritiva de frequência é apresentada a seguir, na análise dos dados.

\section{ANÁLISE DOS DADOS}

Iniciando a petição inauguratória da coleta de dados, investiga-se a contribuição empírica aos objetivos, que corroborem, assim, os objetivos do estudo e a relação biunívoca entre os atores, contrapondo-os com os teóricos, conforme Quadro 3, abaixo, utilizado para análise dos dados.

\section{Quadro 3 - Constructo da pesquisa}

\begin{tabular}{|c|c|c|}
\hline Objetivos & & \\
\hline $\begin{array}{l}\text { Através de um delineamento transversal descritivo e analítico, apre } \\
\text { expansão no Norte do Brasil, analisando o número de cursos na mo } \\
\text { para que o ensino chegue àquela região. }\end{array}$ & $\begin{array}{l}\text { sentar uma perspec } \\
\text { Jalidade e instituiçõe }\end{array}$ & $\begin{array}{l}\text { va sobre a EaD e sua } \\
\text { que têm contribuído }\end{array}$ \\
\hline Foco da Análise & Autores & Operacionalização \\
\hline $\begin{array}{l}\text { As instituições de ensino, nas últimas décadas, sofreram diversas } \\
\text { mudanças: um número significativo de estruturas sociais } \\
\text { estabelecidas não suportaram os impactos e fecharam em face de } \\
\text { orçamentos mais apertados, impacto das inovações tecnológicas, } \\
\text { mudanças dos clientes, demandas estudantis, isolamento } \\
\text { acadêmico, menor demanda do mercado. Isto tem sido parte dos } \\
\text { debates sobre o futuro da educação. }\end{array}$ & $\begin{array}{l}\text { Willard; Wilson, } \\
\text { 2004; VILARINHO; } \\
\text { Paulino, } 2010 .\end{array}$ & Tabelas $1 ; 2 ; 3$. \\
\hline $\begin{array}{l}\text { As instituições que expandiram e têm se saído melhor nos últimos } \\
\text { anos foram as que melhor aplicaram seus recursos em áreas de TI. }\end{array}$ & $\begin{array}{l}\text { Hildreth; Koenig, } \\
2002 .\end{array}$ & Tabelas $1 ; 3$. \\
\hline $\begin{array}{l}\text { A EaD tem reclamado considerável atenção em relação às } \\
\text { mudanças necessárias ao futuro da ciência da educação. De } \\
\text { maneira geral, os educadores reconheceram a necessidade e a } \\
\text { importância de projetar elementos sensíveis à rápida e contínua } \\
\text { mudança tecnológica e desenvolvimento de currículos dinâmicos } \\
\text { que acomodem as exigências do amplo e diversificado mercado de } \\
\text { trabalho. }\end{array}$ & $\begin{array}{l}\text { Partridge et al. } \\
\text { 2010; Partridge; } \\
\text { Yates, } 2012 .\end{array}$ & Tabelas $1 ; 2 ; 3$. \\
\hline $\begin{array}{l}\text { A EaD tradicionalmente tem-se centrado nos estudantes não } \\
\text { tradicionais, como trabalhadores, militares e não residentes, ou } \\
\text { pessoas em regiões remotas que estão incapazes de participar do } \\
\text { ensino tradicional em sala de aula. Na verdade, muitos } \\
\text { profissionais têm obtido seu bacharelado ou licenciatura desta } \\
\text { forma. }\end{array}$ & $\begin{array}{l}\text { Schnitman, 2010; } \\
\text { Crease, 2011; } \\
\text { Degon, } 2010\end{array}$ & $\begin{array}{l}\text { Tabelas } 1 ; 2 ; 3 ; 4 ; 5 ; \\
6 .\end{array}$ \\
\hline O crescimento do emprego de tecnologia na composição de & Vilaça, 2010. & Tabelas $1 ; 2 ; 3$. \\
\hline
\end{tabular}


ensino-aprendizagem em diferentes contextos, nos últimos anos,

tem revolucionado este método peculiar de ensino.

A notoriedade da EaD tem sido detalhada nos resultados do ENADE nos últimos anos, comparando o desempenho dos alunos do Ensino a Distância com o desempenho dos alunos do ensino presencial. Os resultados têm apontado um melhor desempenho nas notas dos alunos de curso de graduação a distância.

A tecnologia é um elemento fundamental da Educação a Distância

Fonte: Dados da pesquisa.

Após a organização do conjunto de variáveis qualitativas nominais e ordinais coletadas a partir do portal emec.mec.gov.br, e organizadas em planilha do Excel ${ }^{\mathrm{TM}}$, foi realizada uma data reduction através do software IBM $^{\circledR}$ SPSS $^{\circledR}$ Statistics para analisar o fenômeno em observação.

\section{RESULTADOS E DISCUSSÃO}

A análise realizada da adoção da modalidade de aprendizagem pela EaD demonstra que, no Norte do Brasil, a mesma vem conquistando espaço de atuação em relação à modalidade de ensino presencial. Atualmente, a $\mathrm{EaD}$, em número de cursos, representa $73,7 \%$ da modalidade versus o ensino presencial. Isto aponta uma diferença que tende a ser equiparada ao número da modalidade presencial muito em breve. A Tabela 1 apresenta a distribuição do ensino no Norte do Brasil em percentuais e concentração, como pode ser evidenciado abaixo.

Tabela 1 - Distribuição do ensino no Norte do Brasil e percentual atendido

\begin{tabular}{|c|c|c|c|c|c|c|c|}
\hline Estado & $\begin{array}{c}\text { No } \\
\text { Cursos } \\
\text { EaD }\end{array}$ & $\begin{array}{c}\text { № Mun. } \\
\text { Atendidos } \\
\text { (\%) }\end{array}$ & $\begin{array}{l}\text { Concentração } \\
\text { EaD na capital }\end{array}$ & $\begin{array}{c}\text { № Cur. Ens. } \\
\text { Presencial }\end{array}$ & $\begin{array}{l}\text { № Mun. } \\
\text { Atendidos }\end{array}$ & $\begin{array}{l}\text { № Curso } \\
\text { EaD+Pres. }\end{array}$ & $\begin{array}{c}\text { № Mun. Atend. } \\
\text { EaD+Pres. }\end{array}$ \\
\hline Acre & 73 & $8(36 \%)$ & $36,2 \%$ & 63 & 22 & 136 & 22 \\
\hline Amapá & 64 & $8(50 \%)$ & $68,2 \%$ & 76 & 4 & 140 & 9 \\
\hline Amazonas & 81 & 17 (27\%) & $38,9 \%$ & 189 & 57 & 270 & 57 \\
\hline Pará & 96 & 44 (30\%) & $20,6 \%$ & 186 & 58 & 282 & 70 \\
\hline Rondônia & 85 & $15(28 \%)$ & $32,2 \%$ & 81 & 12 & 166 & 17 \\
\hline Roraima & 75 & 15 (100\%) & $36,5 \%$ & 81 & 8 & 156 & 15 \\
\hline Tocantins & 91 & $16(11 \%)$ & $15,3 \%$ & 91 & 15 & 182 & 20 \\
\hline TOTAL & 565 & 123 & $43,7 \%$ & 767 & 176 & 1.332 & 210 \\
\hline
\end{tabular}

Fonte: Dados da pesquisa.

É notório que a concentração da EaD, ou polos de apoio, está centralizada nas capitais e ou nas maiores cidades dos estados. Esta distribuição é percebida nos sete estados de maneira análoga, o que reforça a constatação da existência de um gap em relação a distância e ao emprego de tecnologias disponíveis, como a internet. A Tabela 2 mostra, com 
clareza, a frequência da EaD por estado e sua distribuição percentual. Estatisticamente, a distribuição traz um Qui-Quadrado de Pearson com uma significância de 0,548, o que denota que a dispersão observada da EaD deu-se de modo normal na Região Norte, e que as limitações tecnológicas são notórias em toda a região.

Tabela 2 - Frequência de turmas de EaD por Estado.

\begin{tabular}{l|cc}
\hline \multicolumn{1}{c|}{ Estado } & Frequência & Percentual \\
\hline Acre & 186 & $10,6 \%$ \\
Amapá & 143 & $8,1 \%$ \\
Amazonas & 253 & $14,4 \%$ \\
Pará & 407 & $23,2 \%$ \\
Rondônia & 308 & $17,5 \%$ \\
Roraima & 182 & $10,4 \%$ \\
Tocantins & 276 & $15,7 \%$ \\
\hline TOTAL & $\mathbf{1 . 7 5 5}$ & $\mathbf{1 0 0 \%}$ \\
\hline
\end{tabular}

Fonte: Dados da pesquisa.

Encontram-se, atualmente em atividade, 1.755 turmas na modalidade EaD; 94,9\% são cursos oferecidos por instituições de ensino privado, apenas 5,10\% por Instituições Federal de Ensino Superior (IFES) públicas. Esta diferença mostra claramente a inoperância das instituições públicas, e fortalece a exposição metódica sobre a circunstância já mencionada de que:

As instituições de ensino nas últimas décadas sofreram diversas mudanças, um número significativo de estruturas sociais estabelecidas não suportaram os impactos e fecharam em face de orçamentos mais apertados, impacto das inovações tecnológicas, mudanças dos clientes, demandas estudantis, isolamento acadêmico, menor demanda do mercado. Isso tem sido parte dos debates sobre o futuro da educação (WILLARD; WILSON, 2004; VILARINHO; PAULINO, 2010).

As IFES públicas continuam a oferecer estruturas ultrapassadas que não atendem mais às expectativas dos estudantes. Este fenômeno tem sido o diferencial para as instituições privadas, que rapidamente se adequaram a uma demanda mais exigente e ávida por um ensino mais acessível.

Os impactos na crise do ensino têm, na EaD, o realinhamento organizacional, fenômeno demonstrado pelas instituições que expandiram e têm se saído melhor nos últimos anos, conforme já mencionado previamente. Essas instituições foram as que melhor aplicaram seus recursos em áreas de $\mathrm{TI}$, como pode ser percebido na Tabela 3, abaixo. 
Tabela 3 - Instituição IES e sua frequência no Norte do Brasil

\begin{tabular}{|c|c|c|}
\hline IES & FREQUÊNCIA & PERCENTUAL \\
\hline UNISUL & 224 & 12,8 \\
\hline CEUCLAR & 207 & 11,8 \\
\hline UNOPAR & 133 & 7,6 \\
\hline UNIASSELVI & 132 & 7,5 \\
\hline UCB & 122 & 7,0 \\
\hline UNINTER & 111 & 6,3 \\
\hline ULBRA & 104 & 5,9 \\
\hline IFES PÚBLICAS & 90 & 5,1 \\
\hline OUTRAS & 632 & 36,0 \\
\hline TOTAL & 1.755 & 100 \\
\hline
\end{tabular}

Fonte: Dados da pesquisa.

A Tabela 3 apresenta o predomínio das IES com sede no Sul e Sudeste com atuação na Região Norte, revelando uma participação superior a 50\%. Os impactos da crise no ensino têm levado ao realinhamento organizacional de unidades autônomas independentes e a fusões decorrentes da necessidade da redução de custos, da racionalização das estruturas e dos programas. O fenômeno do realinhamento e fusão de instituições privadas também se evidenciou no Brasil nos últimos anos. A Tabela 3 parece refletir o panorama de que algumas instituições aproveitaram as oportunidades, concentrando-se mais na informação e aplicação da Tecnologia da Informação.

O realinhamento organizacional, fenômeno demonstrado pelas instituições que expandiram e adotaram uma forma de ensino mais acessível, tem como público pessoas que disponibilizam de pouco tempo livre e que precisam conciliar emprego e estudo. A EaD oportuniza o acesso à educação e ao crescimento pessoal e profissional por projetar elementos sensíveis à rápida e contínua mudança tecnológica, e por desenvolver currículos dinâmicos que acomodam as exigências do amplo e diversificado mercado de trabalho.

Tabela 4 - Grau

\begin{tabular}{lcc}
\hline \multicolumn{1}{c}{ GRAU } & FREQUÊNCIA & PERCENTUAL \\
\hline Tecnólogo & 829 & 47,2 \\
Licenciatura & 574 & 32,7 \\
Bacharelado & 350 & 19,9 \\
Sequencial & 2 & 0,1 \\
\hline TOTAL & $\mathbf{1 . 7 5 5}$ & $\mathbf{1 0 0}$ \\
\hline
\end{tabular}

Fonte: Dados da pesquisa. 
Essa modalidade tem propiciado mudança na educação, conforme evidenciado na Tabela 4, no que se refere à duração dos cursos superiores, com destaque para os cursos tecnólogos, que oferecem oportunidade de rápida habilitação profissional. Estes representam 47,2\% dos cursos na modalidade EaD. A Tabela 5 apresenta a frequência de cursos, em destaque os de Pedagogia, com 7,2\%; seguido de Administração, com 5,9\%; e Ciências Contábeis, com 4,3\%. Os cursos tecnólogos são em maior número; porém, os de licenciatura e bacharelado são os que mais certificam neste modelo de ensino na região em estudo.

Tabela 5 - Nome do curso e frequência

\begin{tabular}{llccc}
\hline CURSO & GRAU & FREQUÊNCIA & PERCENTUAL & PERCENTUAL/MODALIDADE \\
\hline Pedagogia & Licenciatura & 127 & 7,2 & \multirow{2}{*}{32,7} \\
Outros & Licenciatura & 702 & 25,5 & \\
\hline Administração & Bacharelado & 103 & 5,9 & \multirow{2}{*}{ (9,9 } \\
Ciências contábeis & Bacharelado & 76 & 4,3 & \\
Outros & Bacharelado & 171 & 9,7 & 47,2 \\
\hline Gestão Financeira & Tecnólogo & 71 & 4,0 & \\
Marketing & Tecnólogo & 67 & 3,8 & $\mathbf{1 0 0}$ \\
Outros & Tecnólogo & 691 & 39,4 & \\
\hline TOTAL & - & $\mathbf{1 . 7 5 5}$ & $\mathbf{1 0 0}$ & \\
\hline
\end{tabular}

Fonte: Dados da pesquisa.

Por fim, a Tabela 6 mostra a avaliação do Exame Nacional de Desempenho de Estudantes (ENADE), que integra o Sistema Nacional de Avaliação da Educação Superior (SINAES), e tem o objetivo de aferir o rendimento dos alunos dos cursos de graduação em relação aos conteúdos programáticos, suas habilidades e competências na modalidade da EaD.

Tabela 6 - Avaliação ENADE

\begin{tabular}{cccc}
\hline NOTA & FREQUÊNCIA & PERCENTAGEM & \\
\hline & - & 807 & 46,0 \\
& 1 & 7 & 0,4 \\
2 & 280 & 16,0 \\
3 & 400 & 22,8 \\
4 & 400 & 10,7 \\
5 & 188 & 2,1 \\
SC* & 36 & 2,1 \\
\hline TOTAL & $\mathbf{1 7 3 . 7 5 5}$ & $\mathbf{1 0 0}$ \\
\hline
\end{tabular}

* Sem conceito ENADE (SC)

Fonte: Dados da pesquisa. 
As informações constantes na Tabela 6 traduzem os resultados obtidos a partir da análise do desempenho e do perfil dos estudantes da EaD avaliado pelo ENADE. Mesmo considerando as limitações que os instrumentos utilizados podem apresentar enquanto mecanismo de avaliação de curso, o INEP está convencido de que os dados relativos aos resultados da prova e a opinião dos estudantes podem ser úteis para orientar as ações pedagógicas e administrativas da instituição e dos cursos, uma vez que se constituem em importantes referências para o conhecimento da realidade institucional e para a permanente busca da melhoria da qualidade da graduação, aspectos que ratificam o caráter integrativo inerente à avaliação (INSTITUTO NACIONAL DE PESQUISAS EDUCACIONAIS ANÍSIO TEIXEIRA, 2013).

\section{CONCLUSÃO}

O objetivo proposto foi analisar, através de um delineamento transversal descritivo e analítico, uma perspectiva sobre a $\mathrm{EaD}$ e sua expansão no Norte do Brasil, considerando o número de cursos na modalidade e instituições presentes que têm contribuído para que o ensino chegue à referida Região.

As iniciativas de ensino, apesar das limitações tecnológicas, são notórias em toda a Região Norte. O senso realizado pela ABED demonstra que a EaD, no Brasil, continua crescendo e recomenda a adoção plena desta modalidade de aprendizagem. Apesar do pequeno crescimento em relação ao Sul e ao Sudeste, a Região Norte do país tem experimentado um aumento no acesso à educação superior a populações que, de outra forma, seriam excluídas.

A modalidade EaD trouxe a democratização do ensino e a redução das desigualdades de oportunidades. Porém, o Ensino a Distância é uma modalidade que usa a tecnologia como principal aliada. $\mathrm{O}$ baixo crescimento em relação às demais regiões está evidenciado pela alta concentração da EaD nas capitais. O discurso da democratização da educação nas regiões mais longínquas do Norte do país está limitado ao acesso às novas tecnologias, o que dificulta a redução das desigualdades de oportunidades.

A baixa frequência das IFES públicas no ensino a distância torna evidente as limitações por parte de sua estrutura e formato pedagógico. As instituições privadas 
apresentam uma resposta mais rápida ao novo cenário e à capacidade de reconfiguração. Não se pode negar que a EaD tornou-se um grande filão de mercado, evidenciado por 94,9\% de frequência por IES privadas atuando na modalidade.

O delineamento transversal permite sustentar a tese de que as IES precisam adotar uma ou mais interações de educação pela modalidade EaD para manter a relevância para os estudantes de hoje e alunos do futuro. O governo federal, por sua vez, precisa investir mais na disponibilização de tecnologias, como o acesso à internet por banda larga nos estados e municípios do Norte do país. Além disso, a adoção de tecnologias acessíveis pode promover ainda mais a democratização do ensino.

A Educação a Distância amplia seu alcance e utiliza novas ferramentas de entrega. As preocupações com a sua eficácia não podem ser analisadas através do delineamento transversal. Apesar dos esforços, os programas de Educação a Distância ainda carecem de maior credibilidade.

Algumas perguntas ficam como sugestão para próximas pesquisas: os estudantes concluintes serão reconhecidos no mercado de trabalho? O grande número de cursos atende às demandas do mercado? A qualidade dos programas é satisfatória?

Este estudo não buscou analisar a capacidade de aprendizagem de alunos convencionais versus estudantes na modalidade $\mathrm{EaD}$, nem mesmo a evasão dos estudantes nesta modalidade de ensino. Estudos semelhantes ficam como sugestão para futuras pesquisas.

Por fim, as iniciativas de Ensino a Distância estão muito ligadas à missão educativa da instituição. Para que tal iniciativa tenha sucesso, um plano de avaliação de Educação a Distância, cuidadosamente projetado, é necessário. Uma avaliação dos programas a distância por parte do MEC é imprescindível, bem como a avaliação de pesquisas em grupos focais ou descritivas para aprofundar o conhecimento sobre a satisfação dos alunos com suas experiências com a EaD. Um plano de avaliação de boa educação a distância contribuirá com programas e políticas educacionais futuras.

\section{REFERÊNCIAS}


ALMEIDA, M. E. B. de. Tecnologia e educação a distância: abordagens e contribuições dos ambientes digitais e interativos de aprendizagem. Reunião Anual da Anped, v. 26, 2009.

ALVES, L. Educação a distância: conceitos e história no Brasil e no mundo. Revista Brasileira de Aprendizagem Aberta e a Distância, v. 10, 2011.

ASSOCIAÇÃO BRASILEIRA DE EDUCAÇÃO A DISTÂNCIA. Censo EAD.BR: relatório analítico da aprendizagem a distância no Brasil 2012. Curitiba: Ibpex, 2013.

BATES, A. W. Technology, open learning and distance education. 2.ed., New York: Routledge, 2005.

BELLONI, M. L. Educação a distância. 5. ed. Campinas: Autores Associados, 2009.

BELLONI, M. L. Ensaio sobre a educação a distância no Brasil. Educação \& sociedade, v. 23, n. 78, p. 117-142, 2002.

BRASIL. Decreto № 5.622, de 19 de dezembro de 2005. Regulamenta o art. 80 da Lei no. 9.394, de 20 de dezembro de 1996, que estabelece as diretrizes e bases da educação nacional. Disponível em: <http://portal.mec.gov.br/seed/arquivos/pdf/dec_5622.pdf>. Acesso em: 01 out. 2013.

BRASIL. Lei no 9.394, de 20 de dezembro de 1996. Estabelece as Diretrizes e Bases da Educação Nacional. Diário Oficial [da República Federativa do Brasil], Brasília, DF, v. 134, n. 248, 23 dez. 1996. Seção 1, p. 27834-27841.

CASEY, D. M. The historical development of distance education through technology. TechTrends, v. 52, n. 2, p. 45, 2008.

COSTA, K. da S.; FARIA, G. G. EaD, sua origem histórica, evolução e atualidade brasileira face ao paradigma da educação presencial. In: CONGRESSO INTERNACIONAL ABED DE EDUCAÇÃO A DISTÂNCIA, 14. 2008, Santos. Anais eletrônicos... ABED: Santos, 2008. Disponível em: <http://www. abed. org. br/congresso2008/tc/552008104927AM>. Acesso em: 01 out. 2013.

CREASE, R.; PYMM, B.; HAY, L. Bridging the gap-engaging distance education students in a virtual world. In: Ascilite Conference, p. 307-313. 2011

DEGON, R. Distance learning for the RN first assistant. AORN, v. 91, n. 1, p. 146-153, 2010.

FARIA, A. A.; SALVADORI, A. A Educação a Distância e Seu Movimento Histórico no Brasil. Revista das Faculdades Santa Cruz, v. 8, n. 1, 2010.

GARRISON, D. R.; ANDERSON, T.; ARCHER, W. A theory of critical inquiry in online distance education. In: MOORE, Michael Grahame; ANDERSON, William G. (Ed.). Handbook of distance education. New Jersey: Lawrence Erlbaum Associates, 2003. p. 113-127.

GATTI, B. A. Análise das políticas públicas para formação continuada no Brasil, na última década. Revista Brasileira de Educação, v. 13, n. 37, p. 57-70, 2008. 
GUNAWARDENA, C. N.; MCISAAC, M. S. Distance education. Handbook of research for educational communications and technology, v. 2, p. 355-395, 2004.

HILDRETH, C. R.; KOENIG, M. Organizational realignment of LIS programs in academia: From independent standalone units to incorporated programs. Journal of Education for Library and Information Science, v. 43, n. 2, p. 126-133, 2002.

HOLMBERG, B. et al. The evolution, principles and practices of distance education. Bis, 2005.

HOLMBERG, B. Growth and structure of distance education. London: Croom Helm, 1986.

INSTITUTO BRASILEIRO DE GEOGRAFIA E ESTATÍ́sTICA. Censo demográfico 2010. IBGE, 2010.

INSTITUTO BRASILEIRO DE GEOGRAFIA E ESTATÍSTICA. Síntese de indicadores sociais. IBGE, 2008.

INSTITUTO NACIONAL DE ESTUDOS E PESQUISAS EDUCACIONAIS ANÍSIO TEIXEIRA. Relatório ENADE. Brasília, 2013.

MATTHEWS, D. The origins of distance education and its use in the United States. The Journal, v. 27, n. 2, 1999.

MENDES, V. A expansão do ensino a distância no Brasil: democratização do acesso? In: SIMPÓSIO BRASILEIRO POLÍTICA E ADMINISTRAÇÃO DA EDUCAÇÃO, 25., 2011, São Paulo, Anais eletrônicos... São Paulo: ANPAE, 2011. p. 1-11

MESSIAS, P. P. Educação a distância: o ponto de vista do educando em gestão em saúde EAD. Anated, 2010.

MONOLESCU, D. et al. The distance education evolution: Issues and case studies. IGI Global, 2004.

MOORE, M. G.; KEARSLEY, G. EAD: uma visão integrada. São Paulo: Thomson Learning, 2007.

MOORE, M. G.; KEARSLEY, G. Distance education: a systems view of online learning. CengageBrain.com, 2011.

MORAN, J. MI. Avaliação do ensino superior a distância no Brasil. E-Learning, v. 39, 2009.

NASSEH, B. A brief history of distance education. Adult Education in the News, 1997.

PARSAD, B. et al. Distance education at degree-granting postsecondary institutions: 200607. IES: Washington, 2008.

PARTRIDGE, H. L. et al. Charting future directions: towards cohesive and sustainable library and information science education in Australia. Cooperation and Collaboration in Teaching and Research: Trends in LIS Education. IFLA-ALISE-EUCLID satellite meeting, World Library and Information Congress: In: IFLA GENERAL CONFERENCE AND ASSEMBLY, 76., 2010.

Proceedings...Boras, Sweden, 2010. 
PARTRIDGE, H. L.; YATES, C. A framework for the education of the information professions in Australia. Australian Library Journal, v. 61, n. 2, p. 81-94, 2012.

POTASHNIK, M.; CAPPER, J. Distance education: Growth and diversity. Finance and development, v. 35, p. 42-45, 1998.

SABA, F. Distance education theory, methodology, and epistemology: a pragmatic paradigm. In: MOORE, Michael Grahame; ANDERSON, William G. (Ed.). Handbook of distance education. New Jersey: Lawrence Erlbaum Associates, 2003. p. 3-20.

SCHNITMAN, I. M. O perfil do aluno virtual e as teorias de estilos de aprendizagem. Faculdade de Tecnologia e Ciências Instituição (FTC). In: SIMPÓSIO HIPERTEXTO E TECNOLOGIAS NA EDUCAÇÃO, 2010. Anais eletrônicos... Disponível em: http://www.ufpe.br/nehte/simposio/anais/Anais-Hipertexto-2010/Ivana-MariaSchnitman.pdf. Acesso em: 28 set. 2013.

SIMONSON, M. R. et al. Teaching and Learning at a Distance: Foundations of Distance Education. Simonson, Upper Saddle River, NJ: Prentice Hall, 2000.

STRAIGHTERLINE. Infographic history of distance education. Disponível em: http://www.straighterline.com/online-education-resources/online-educationtools/infographic-history-of-distance-education/. Acesso em: 29 set. 2013.

VIANNEY, J. A ameaça de um modelo único para a EaD no Brasil. Colabor@-A Revista Digital da CVA-RICESU, v. 5, n. 17, 2008.

VILAÇA, M. L. C. Educação a distância e tecnologias: conceitos, termos e um pouco de história. Revista Magistro, v. 2, n. 1, 2010.

VILARINHO, L. R. G.; PAULINO, C. L. Educação a distância no ensino superior brasileiro: das experiências pioneiras ao sistema de rede. Revista Eletrônica de Educação, v. 4, n. 1, p. 6479, 2010.

WILLARD, P.; WILSON, C. S. Australian professional library and information studies education programs: changing structure and content. Australian Academic and Research Libraries, v. 35, n. 4, p. 273-288, 2004. 